\title{
Oral acyclovir induced hypokalemia and acute tubular necrosis a case report
}

\author{
Jonathan S. Chávez-Iñiguez ${ }^{1,2^{*}}$ (D, Ramón Medina-Gonzalez ${ }^{1}$, Lilia Aguilar-Parra ${ }^{3}$, Eduardo J. Torres-Vázquez ${ }^{1,2}$, \\ Pablo Maggiani-Aguilera ${ }^{1,2}$, Enrique Cervantes-Pérez ${ }^{1,2}$ and Guillermo García-García ${ }^{1,2}$
}

\begin{abstract}
Background: Acyclovir is one of the most common prescribed antiviral drugs. Acyclovir nephrotoxicity occurs in approximately $12-48 \%$ of cases. It can present in clinical practice as acute kidney injury (AKI), crystal-induced nephropathy, acute tubulointerstitial nephritis, and rarely, as tubular dysfunction. Electrolytes abnormalities like hypokalemia, were previously described only when given intravenously.

Case presentation: A 54 year-old female presented with weakness and lower extremities paresis, nausea and vomiting after receiving oral acyclovir. Physical examination disclosed a decrease in the patellar osteotendinous reflexes $(++/++++)$. Laboratory data showed a serum creatinine level of $2.1 \mathrm{mg} / \mathrm{dL}$; serum potassium $2.1 \mathrm{mmol} / \mathrm{L}$. Kidney biopsy was obtained; histological findings were consistent with acute tubular necrosis and acute tubulointerstitial nephritis. The patient was advised to stop the medications and to start with oral and intravenous potassium supplement, symptoms improved and continued until serum potassium levels were $>3.5 \mathrm{meq} / \mathrm{L}$.

Conclusions: The case reported in this vignette is unique since it is the first one to describe hypokalemia associated to acute tubular necrosis induced by oral acyclovir.
\end{abstract}

Keywords: AKI, Acyclovir, Hypokalemia

\section{Background}

Drug-induced kidney injury is a frequent adverse effect seen in clinical practice by different mechanisms that commonly lead to acute kidney injury (AKI) [1]. In a large cohort study of patients with community-acquired AKI (CA-AKI), nephrotoxic drugs where assumed in $59.9 \%$ of the cases [2].

Adverse drug reactions (ADRs) have a major impact on public health. Between 1999 and 2008, the annual number of ADRs increased $76.8 \%$, and a two-fold increase in drug nephrotoxicity was observed [3].

Antiviral drugs like acyclovir, are known to induce AKI when administrated intravenously. Risk factors for developing acyclovir-induced nephrotoxicity include hypovolemia, rapid intravenous infusion, concurrent AKI prior to drug administration, excess medication dosage in

\footnotetext{
* Correspondence: jonarchi_10@hotmail.com

${ }^{1}$ Servicio de Nefrología, Hospital Civil de Guadalajara Fray Antonio Alcalde,

Guadalajara, Mexico

${ }^{2}$ Centro Universitario de Ciencias de la Salud CUCS, Universidad de

Guadalajara, Guadalajara, Mexico

Full list of author information is available at the end of the article
}

relation to renal function, and concurrent use of other nephrotoxic agents [4]. Severe nephrotoxicity occurs in approximately $12-48 \%$ of the cases [5]. However, the potential damage induced by oral administration remains unclear. In one study aimed to assess hospital admission due to AKI within 30 days after prescription of oral acyclovir, it was found that neither the use of acyclovir nor valacyclovir was associated with a higher risk of AKI, in comparison to famcyclovir $[6,7]$.

Potassium disturbances are a well-known harmful consequence of drug intake. Drug-induced hypokalemia is most frequently caused by diuretic [8] glucocorticoid [9], and laxative administration [10].

Alternatively, it may be the result of an increased intracellular potassium influx induced by the use of sympathomimetic drugs [11], and insulin [12].

We report a unique case of oral Acyclovir induced hypokalemia and CA-AKI due to acute tubular necrosis.

(c) The Author(s). 2018 Open Access This article is distributed under the terms of the Creative Commons Attribution 4.0 International License (http://creativecommons.org/licenses/by/4.0/), which permits unrestricted use, distribution, and reproduction in any medium, provided you give appropriate credit to the original author(s) and the source, provide a link to the Creative Commons license, and indicate if changes were made. The Creative Commons Public Domain Dedication waiver (http://creativecommons.org/publicdomain/zero/1.0/) applies to the data made available in this article, unless otherwise stated. 


\section{Case presentation}

\section{Clinical history and laboratory data}

A 54 year-old female presented to the outpatient clinic with weakness and lower extremities paresis, nausea and three times vomiting, after receiving clindamycin, dicloxaciline, and oral acyclovir $400 \mathrm{mg}$ each $8 \mathrm{~h}$ were prescribed to treat a dental abscess. Relevant past medical history included allergy to penicillin and smoking for 20 years. Physical examination disclosed good hydration status, decrease in the patellar osteotendinous reflexes $(++/++++)$. Initial laboratory data showed a serum creatinine level of $2.1 \mathrm{mg} / \mathrm{dL}$; blood urea nitrogen $86.4 \mathrm{mg} / \mathrm{dL}$; serum potassium
$2.1 \mathrm{mmol} / \mathrm{L}$, sodium $134 \mathrm{mmol} / \mathrm{L}$, phosphorus $1.7 \mathrm{mg} / \mathrm{dL}$, and magnesium $2.15 \mathrm{mg} / \mathrm{dL}$. (Table 1).

\section{Additional investigations}

The patient was advised to stop the medications and to start with oral potassium supplement. She noticed improvement of the weakness; however, due to persistent hypokalemia, the patient was admitted to the hospital for further evaluation; new blood test showed a serum creatinine level of $1.7 \mathrm{mg} / \mathrm{dL}$ and blood urea nitrogen $76.3 \mathrm{mg} / \mathrm{dL}$; serum potassium $2.5 \mathrm{mmol} / \mathrm{L}$, sodium $139 \mathrm{mmol} / \mathrm{L}$, phosphorus $2 \mathrm{mg} / \mathrm{dL}$, and magnesium $1.88 \mathrm{mg} / \mathrm{dL}$; urine sediment was unremarkable; $24 \mathrm{~h}$

Table 1 Laboratory data

\begin{tabular}{|c|c|c|c|c|c|c|c|}
\hline Parameters & Baseline & Day 3 & Day 11 & Day 13 & Day 14 & Day 15 & Reference range \\
\hline Hemoglobin (g/dL) & 13.3 & 12.8 & 12.5 & 10.82 & 11.1 & - & $12.0-16.0$ \\
\hline Hematocrit, \% & 35.4 & 33.8 & 36.7 & 31.8 & 32.45 & - & $37-47$ \\
\hline Platelets, K/mcl & 326,000 & 318,000 & 253,700 & 207,100 & 203,600 & - & $150,000-500,000$ \\
\hline White blood cells (K/mcl) & 6290 & 5790 & 4780 & 3860 & 4120 & - & $3600-11,600$ \\
\hline Glucose (mg/dL) & 136 & 123 & 100 & 159 & 139 & - & 60-99 \\
\hline Urea (mg/dL) & 86.4 & 76.3 & 63.8 & 45.8 & 42 & - & $16.6-48.5$ \\
\hline Creatinine (mg/dL) & 2.1 & 1.7 & 1.18 & 1.1 & 1.14 & - & $0.5-1.2$ \\
\hline Uric acid (mg/dL) & 8.1 & 7.3 & 5.4 & 4.8 & 5 & - & $2.4-5.7$ \\
\hline Potassium (mmol/L) & 2.1 & 2.5 & 3 & 2.8 & 2.8 & 3.1 & $3.5-5.1$ \\
\hline Sodium (mmol/L) & 134 & 139 & 140 & 140 & 141 & 139 & $135-145$ \\
\hline Calcium (mmol/L) & 10.1 & 9.7 & 9.3 & 8.5 & 8.5 & 8.9 & $8.6-10$ \\
\hline Cloride (mmol/L) & 89 & 95 & 106 & 108 & 109 & 102 & $98-107$ \\
\hline Phosphorus (mg/dL) & 1.7 & 2 & 2.9 & 3 & 3.4 & 2.2 & $2.5-4.5$ \\
\hline Magnesium (mg/dL) & 2.15 & 1.88 & - & - & - & - & $1.6-2.6$ \\
\hline Albumin (g/dL) & 4.9 & 4.8 & 4.1 & 3.3 & 3.5 & - & $3.5-5.2$ \\
\hline Blood pH & - & 7.45 & - & - & - & - & $7.35-7.45$ \\
\hline $\mathrm{CO}_{2} \mathrm{mmHg}$ & - & 37.2 & - & - & - & - & $35-45$ \\
\hline $\mathrm{HCO}_{3}(\mathrm{mmol} / \mathrm{L})$ & - & 25.3 & - & - & - & - & $23-25$ \\
\hline Urine pH (dipstick) & 7 & 7 & 6.5 & - & - & - & $5.0-8.0$ \\
\hline Dipstick protein, mg/dL & negative & negative & negative & - & - & - & Negative \\
\hline Red blood cells (dipstick) & negative & negative & negative & - & - & - & Negative \\
\hline leukocyte esterase (dipstick) & negative & negative & 15 & - & - & - & Negative \\
\hline Urinary casts & none & none & None & - & - & - & None \\
\hline Urine protein (g/day) & - & - & - & 0.23 & - & - & \\
\hline Urine potassium (mmol/day) & - & 49 & - & 86 & - & - & $<30$ \\
\hline Urine sodium (mmol/day) & - & 86 & - & 162 & - & - & \\
\hline Urine calcium (mmol/day) & - & 89 & - & 57 & - & - & \\
\hline Urine phosphorus (mg/day) & - & - & - & 143 & - & - & \\
\hline Spot urine potassium (mEq/L) & - & 20.1 & - & 30 & - & - & $<15$ \\
\hline Spot urine sodium (mEq/L) & - & 37 & - & 57 & - & - & $<20$ \\
\hline Spot urine calcium (mEq/L) & - & - & - & 1.73 & - & - & \\
\hline Spot urine phosphorus (mEq/L) & - & - & - & 4.6 & - & - & \\
\hline
\end{tabular}


urine potassium was $49 \mathrm{mEq} /$ day, sodium $86 \mathrm{mEq} /$ day, and calcium $89 \mathrm{mg} /$ day. A renal ultrasound showed a normal-size kidney, without hydronephrosis. Kidney biopsy was performed.

\section{Kidney biopsy}

Two fragments of kidney tissue were obtained (Fig. 1), By stereoscopic evaluation 11 glomeruli were identified. By light microscopy 9 glomeruli were observed; three were globally sclerosed and the remaining glomeruli were normal. Tubular atrophy was seen in $15-20 \%$ of the tubules; the remaining tubules showed vacuolated, granular cytoplasm, focal sloughing of the epithelium, and regenerative changes of the brush edge of tubular cells and hyaline casts (Fig. 1a). By Masson's trichrome stain (Fig. 1b and c), the interstitium exhibited $0-15 \%$ fibrosis, with inflammatory infiltrate by lymphocytes, plasma cells, and few eosinophils, that penetrated the tubular epithelium. Arterioles and medium-caliber arteries were permeable without vasculitis or thrombi. By Jones (Fig. 1d) tubule-interstitial nephritis infiltrated with abundant inflammatory cells were observed. Immunofluorescence (Fig. 1e) was negative for IgM, IgG, IgA, C3c, C1q, kappa, lambda, fibrinogen, and albumin. Histological findings were consistent with acute tubular necrosis and acute tubulointerstitial nephritis.

\section{Clinical follow-up}

Due to persistent hypokalemia oral and intravenous potassium replacement was started with good tolerability and no adverse events, symptoms improved; the patient was discharged 4 days later with a serum potassium of $3.1 \mathrm{mEq} / \mathrm{L}$; oral replacement of potassium was continued until serum potassium levels were $>3.5 \mathrm{meq} / \mathrm{L}$, after few days later she restart her normal life.

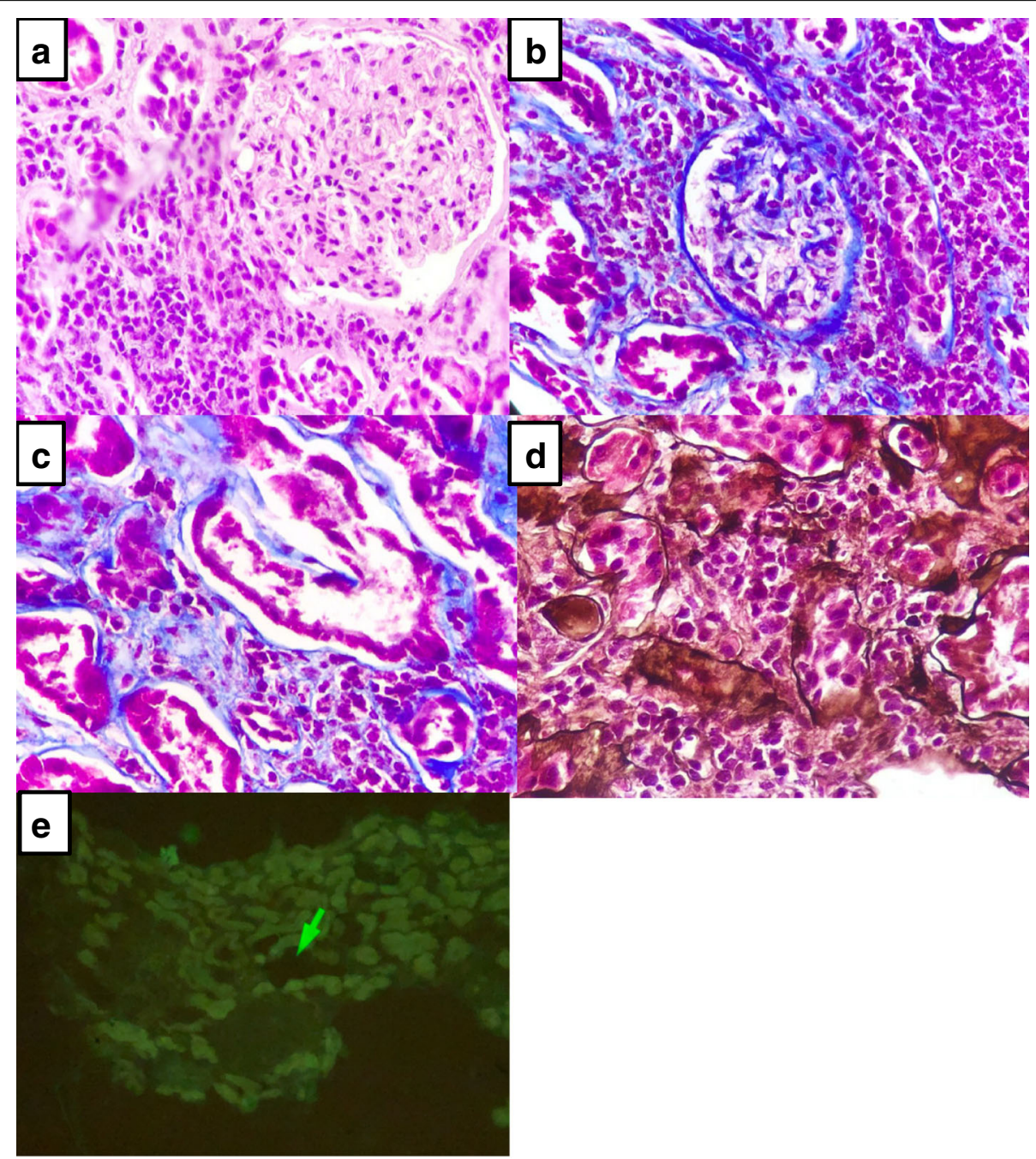

Fig. 1 a and $\mathbf{b}$ Mesangium without proliferation and open capillaries, tubules with brush edge loss and cytoplasmic vacuolization, with diffuse inflammatory infiltrate. $\mathbf{d}$ Acute tubular necrosis, (c) tubulointerstitial nephritis with abundant inflammatory infiltrate and (e) immunofluorescence negative for immune complexes 


\section{Diagnosis}

Hypokalemia and acute kidney injury due to oral acyclovir.

\section{Discussion and Conclusions}

Ramírez et al. have described acyclovir and other drug-induce causes of hypokalemia. Drug-induced severe potassium disturbances were found in $32.3 \%$ of the cases, and in $23 \%$ were lethal; hypokalemia was present in $23.4 \%$ of life-threatening potassium disturbances [7].

Intravenous acyclovir is the most common therapy against herpes virus; it can induce crystalluria and lead to AKI. In a population-based study, hypokalemia developed in $46 \%$ of patients receiving iv acyclovir compared to $21 \%$ in the control group; individuals with a previous normal potassium levels, altered estimated glomerular filtration rate, or previous use of diuretics were at higher risk of developing hypokalemia [13]. They suggested that iv acyclovir induces hypokalemia by reduced renal plasma flow and/or by crystal-induced distal tubular damage.

Other possible mechanisms include tubular dysfunction mediated by aldheyde metabolite of acyclovir; this complication could explain the urinary loss of potassium and others electrolytes (Fig. 2a); by direct injury to the renal tubular epithelia causing tubular cell degeneration and sloughing. Indeed, renal biopsy findings of patients with acyclovir toxicity include bulging of tubular cells, dilated tubular lumens, loss of proximal-distal tubular differentiation, flattening and vacuolization of epithelial cells, and epithelial cells mitoses [5] (Fig. 2b); and crystalluria, which usually develops $24-48 \mathrm{~h}$ after the initiation of acyclovir therapy due to its low solubility in urine. Severe intraparenchymal crystal precipitation can cause interstitial congestion and hemorrhage, leading to a decrease of renal blood flow (Fig. 2c) [14].

Acyclovir does not seem to affect the tubular handling of creatinine, suggesting that the pronounced, transient

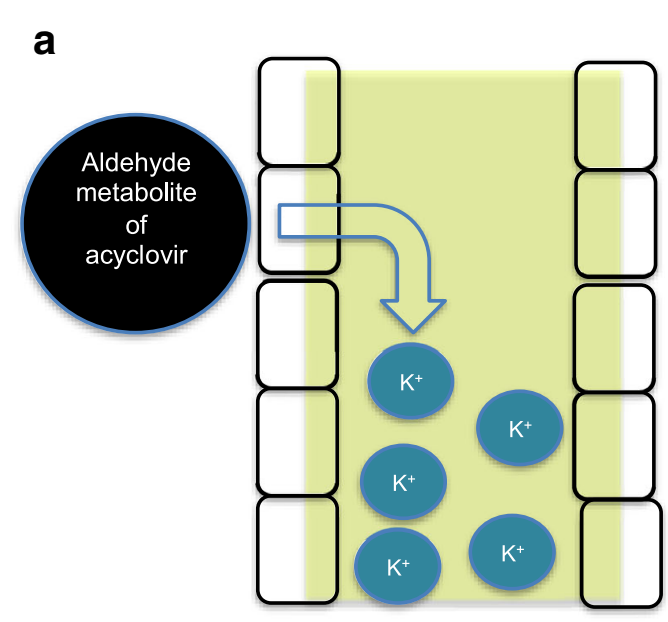

b
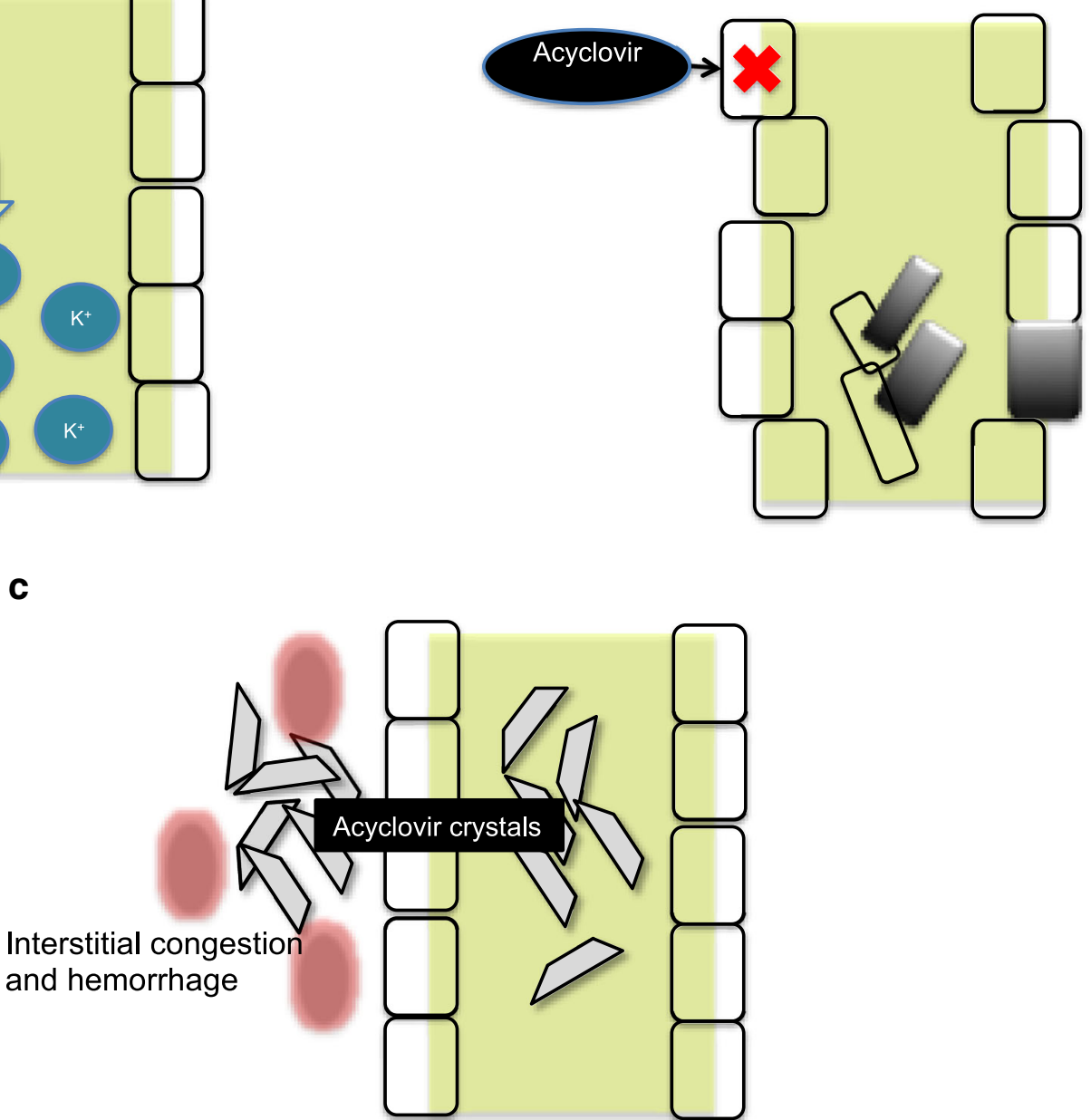

Fig. 2 Effects of acyclovir on the renal parenchyma. a Tubular dysfunction and electolyte loss; b Direct injury to the renal tubular cell, necrosis and tubular obstruction; c Crystalluria and crystals in the tubular parenchyma 
elevation in plasma creatinine, may be due solely to decreased glomerular filtration rate (GFR) as a result of renal dysfunction [5].

To prevent the possible the adverse effects of acyclovir, it has been recommended to establish euvolemia, slow intravenous infusion (over 1-2 h), adjusting the dose according to renal function, and to avoid the use of concomitant nephrotoxic agents prior to acyclovir administration [4].

It is important to mention that a great limitation of the presentation of our case is that we cannot adjudge causality for the intake of acyclovir, but there is biological and clinical plausibility that sustains this event. Strength of our case is that we have obtained renal tissue for histological analysis, since it is not common to perform a kidney biopsy in the presence of acute kidney Injury secondary to drugs.

The detection, reporting, and prevention of ADRs due to acyclovir, are essential to provide appropriate, safe, and effective therapy with this drug.

Acyclovir nephrotoxicity occurs in approximately 12$48 \%$ of cases, is associated with 3 patterns of kidney injury: tubular dysfunction and electrolyte loss, direct injury to the renal tubular cells and crystalluria, in $46 \%$ of patient that recive IV acyclovir develop hypokalemia. Probably both IV and oral acyclovir are associated with hypokalemia. To prevent the possible the adverse effects of acyclovir, establish euvolemia, slow intravenous infusion, adjusting the dose to renal function, avoid concomitant nephrotoxic agents. Early detection of renal and tubular dysfunction of ADRs due to acyclovir, are essential to provide appropriate, safe, and effective therapy with this drug.

\section{Abbreviations}

ADRs: Adverse drug reactions; AKI: Acute kidney injury; CA-AKI: Communityacquired acute kidney injury; GFR: Glomerular filtration rate; IV: Intravenous

\section{Acknowledgements}

none.

\section{Funding}

We don't have any funding.

Availability of data and materials

We have all the clinical and histological data.

\section{Authors' contributions}

JSCI, RMG, GGG contribute in conception, design, acquisition of data, analysis and interpretation of data, been involved in drafting the manuscript, given final approval of the version to be published. JSCI was responsible for creating the images. LGAP, EJTV, PMA and ECP contribute in acquisition of data, analysis and interpretation of data, been involved in drafting the manuscript, given final approval of the version to be published. All authors read and approved the final manuscript.

Ethics approval and consent to participate

not applicable.

\section{Consent for publication}

Written informed consent was obtained from the patient for publication of this Case Report and any accompanying images. A copy of the written consent is available for review by the Editor of this journal.

\section{Competing interests}

All authors declare that they have no competing interest.

\section{Publisher's Note}

Springer Nature remains neutral with regard to jurisdictional claims in published maps and institutional affiliations.

\section{Author details}

${ }^{1}$ Servicio de Nefrología, Hospital Civil de Guadalajara Fray Antonio Alcalde, Guadalajara, Mexico. ${ }^{2}$ Centro Universitario de Ciencias de la Salud CUCS, Universidad de Guadalajara, Guadalajara, Mexico. ${ }^{3}$ Servicio de Medicina Interna, Hospital General de Occidente, Guadalajara, Mexico.

Received: 20 July 2018 Accepted: 25 October 2018

Published online: 14 November 2018

\section{References}

1. Izzedine H, Launay-Vacher V, Deray G. Antiviral drug-induced nephrotoxicity. Am J Kidney Dis. 2005;45(5):804-17.

2. Wang Y, Wang J, Su T, Qu Z, Zhao M, Yang L. ISN AKF Oby25 China consortium. Community-acquired acute kidney injury: a Nationwide survey in China. Am J Kidney Dis. 2017:69(5):647-57. https://doi.org/10.1053/j.ajkd.2016.10.034.

3. Wu TY, Jen MH, Bottle A, Molokhia M, Aylin P, Bell D, Majeed A. Ten-year trends in hospital admissions for adverse drug reactions in England 1999-2009. J R Soc Med. 2010;103(6):239-50. https://doi.org/10.1258/jrsm.2010.100113.

4. Fleischer R, Johnson M. Acyclovir nephrotoxicity: a case report highlighting the importance of prevention, detection, and treatment of acyclovir-induced nephropathy. Case Rep Med 2010; 2010. pii: 602783. doi:https:/doi.org/10. $1155 / 2010 / 602783$

5. Yildiz C, Ozsurekci Y, Gucer S, Cengiz AB, Topaloglu R. Acute kidney injury due to acyclovir. CEN Case Rep. 2013;2(1):38-40. https://doi.org/10.1007/ s13730-012-0035-0.

6. Lam NN, Weir MA, Yao Z, Blake PG, Beyea MM, Gomes T, Gandhi S, Mamdani M, Wald R, Parikh CR, Hackam DG, Garg AX. Risk of acute kidney injury from oral acyclovir: a population-based study. Am J Kidney Dis. 2013 May;61(5):723-9. https://doi.org/10.1053/j.ajkd.2012.12.008.

7. Ramírez E, Rossignoli T, Campos AJ, Muñoz R, Zegarra C, Tong H, Medrano N, Borobia AM, Carcas AM, Frías J. Drug-induced life-threatening potassium disturbances detected by a pharmacovigilance program from laboratory signals. Eur J Clin Pharmacol. 2013;69:97-110. https://doi.org/10.1007/ s00228-012-1303-9.

8. Knochel JP. Diuretic-induced hypokalemia. Am J Med. 1984;77:18-27.

9. Edwards CR, Walker BR, Benediktsson R, Seckl JR. Congenital and acquired syndromes of apparent mineralocorticoid excess. J Steroid Biochem Mol Biol. 1993;45:1-5.

10. Meyers AM, Feldman C, Sonnekus MI, Ninin DT, Margolius LP, Whalley NA Chronic laxative abusers with pseudoidiopathic oedema and autonomous pseudo-Bartter's syndrome: a spectrum of metabolic madness, or new lights on an old disease. S Afr Med J. 1990;78:631-6.

11. Bremner P, Burgess C, Beasley R, Woodman K, Marshall S, Crane J, Pearce N. Nebulized fenoterol causes greater cardiovascular and hypokalaemic effects than equivalent bronchodilator doses of salbutamol in asthmatics. Respir Med. 1992:86:419-23.

12. Bradberry SM. Vale JA disturbances of potassium homeostasis in poisoning. J Toxicol Clin Toxicol. 1995:33(4):295-310

13. Drawz PE, Perez F, Bonomo RA. Acyclovir induced hypokalemia. J Clin Virol. 2013 Feb;56(2):177-8. https://doi.org/10.1016/j.jcv.2012.10.002

14. Mason W, Nickols H. Crystalluria from acyclovir use. N Engl J Med. 2008;358:e. https://doi.org/10.1056/NEJMicm066726. 